\title{
OUTLET WORK OPTIMIZATION IN FLOOD CONTROL RESERVOIRS
}

\author{
G. CIARAVINO \& L. CIARAVINO \\ Department of Hydraulic, Geotechnical and Environmental Engineering, \\ University of Naples Federico II, Italy.
}

\begin{abstract}
An examination of the general and hydrological planning criteria for artificial reservoirs clarifies the importance of choosing the correct type of outlet works both for stored volume management and for flooding events control. This choice becomes even more important, if we consider the effects of the climate change we have seen in recent years on extreme events. In this paper, the hydraulic operation of an extremely functional outlet work is studied using a physical model. The work is composed of an uncontrolled spillway and a mid-level outlet unified into a single structure. In particular, it proves of extreme interest both in the lamination of flood events and also in reducing the global costs of outlet works. The tests have highlighted the outstanding hydraulic operation of the works under any condition and, in particular, when the spillway flow and the mid-level outlet flow converge into a single duct.
\end{abstract}

Keywords: Flood control, hydraulic structures, physical model, water management.

\section{INTRODUCTION}

The climate change phenomena we have witnessed in recent years are substantially modifying the impact of flood events and the frequency with which they occur. These factors need to be taken into account in determining reservoir capacities and in the design of artificial reservoir outlet works. In the planning phase of an artificial reservoir (whatever use it is destined for), the problem of correctly establishing the type and the size of the outlet works has to be solved by referring to the maximum estimated flood event, which occurs when the water level $Y_{L}$ in the reservoir already corresponds to the maximum live storage capacity [1]. It is also necessary to make sure that the water surface in the reservoir never exceeds the assigned level $Y_{\max }$ corresponding to the maximum flood event. When a reservoir is employed both for the management of water flow and for the active protection of downstream areas (an occurrence that is notoriously becoming ever more common because of climate change) to reduce the flood wave impact, it is usually necessary to store a volume of water $W_{\max }$, exceeding the level $Y_{L}[2,3]$. In this case, once the planning phase is completed, it is necessary to compare the increased building cost of a dam with the savings resulting from both outlet works and stream-bed protection works, to choose the most convenient outlet works. The skill for a designer, therefore, lies in identifying the best outlet scheme that allows this objective to be reached successfully. The task is not always easy since the work may be subject to restrictions that impose substantially different boundary conditions than those that led to the determination of normally adopted design rules. In such cases, before producing a prototype, the study of down-scaled physical models represents a valid aid for the designer, at least in building more technically challenging and expensive works. It must be stressed that it is not rare for studies on models to clarify problems the solutions to which assume a more general value.

In the present paper, the analysis, also from the hydrological point of view, of the general criteria for planning outlet works in flood control reservoirs has preceded the study, with a physical model, of a particular outlet work characterized by a remarkable functionality (also in terms of safeguarding the environment) as well as an uncommon reduction of costs. 


\section{GENERAL CRITERIA FOR PLANNING OUTLET WORKS}

The main outlet devices of an artificial reservoir normally comprise uncontrolled spillway crests [1]. Thus, with increasing flow rate in the successive time intervals $\Delta t$, it is necessary for the head on the crests to increase from an initial value of $h$ to a value of $h+\Delta h$, so that the outlet flow rate $Q_{o}$ increases by $\Delta Q_{o}$. Consequently, the stored volume in the reservoir exceeding the level of maximum live storage capacity $Y_{L}$ will increase from a value of $W$, corresponding to $h$, to the value of $W+\Delta W$ corresponding to $h+\Delta h$. As a result, in the subsequent time intervals $\Delta t$, the water volume $\Delta D_{o}$ and the average flow rate $Q_{o}=\Delta D_{o} / \Delta t$, discharged by the outlet device, are respectively lower than the volume of water $\Delta D_{i}$ and the average water flow rate $Q_{i}=\Delta D_{i} / \Delta t$ entering the reservoir. In practice, with an assigned overall length $L$ of the crest, it is possible to test two different situations, which will be referred to as hypothesis $\mathrm{A}$ and hypothesis $\mathrm{B}$.

Under hypothesis A, the volume of water contained in the reservoir at the early phase of a flood represents a high percentage of the inflow. Consequently, there are some remarkable differences between the inflow $Q_{i}$ and the outflow $Q_{o}$ with $Q_{o}<Q_{i}$. As the flood peek approaches, however, the volumes $\Delta W$ stored in the reservoir become irrelevant compared to those of the incoming flood $\Delta D_{i}$ : so the outlet flow rate increases, becoming practically identical to the inlet flow rate of the flood. In this case, the result is $Q_{\text {omax }}=Q_{\text {imax }}$.

Under hypothesis B, the volumes stored in the reservoir are greater than those in hypothesis A and, percentagewise, remain considerable even as the flood peak approaches. The outflow $Q_{o}$ is clearly lower than the inflow $Q_{i}$, reaching the maximum value of $Q_{\text {omax }}<Q_{\text {imax }}$ with a notable delay compared to the flood peak, when the flow rate $Q_{i}$ entering the reservoir is already decreasing. Under this hypothesis, the flood wave is mitigated, with a percentage reduction of the flow at flood peak equal to $R_{Q}=Q_{\text {omax }} / Q_{\text {imax }}$, which is certainly significant in terms of determining the proportions of the outlet works.

In cases where hypothesis A occurs, because the maximum outlet flow rate $Q_{\text {omax }}$ practically coincides with the maximum inlet flow rate, the latter is used as a reference. The outlet works are thus designed in such a way as to never allow the water surface in the reservoir to rise above the point of $Y_{\max }$, used as a reference for the level of the largest flood event estimated. The top of the dam is set above the $Y_{\max }$ level by a difference $\delta$ (for security reasons) to safeguard against any wave movement that may occur on the water surface of the artificial lake. Furthermore, the validity of the $Q_{\text {imax }}$ estimation is strictly correlated to the basic data used to deduce it [4-6]. It cannot be excluded that this value of $Q_{\text {imax }}$ could be underestimated, and that, as a result, the real hydrological magnitude may have larger values than those estimated. It must also be considered that there is a risk that the assumed magnitude of hydrological quantities may be exceeded in the case of exceptional pluviometrical events. In practice, this is accounted for by correctly establishing the difference $\delta$ between the maximum flood level $Y_{\max }$ and the top of the dam. To summarize, correspondingly to variations in the value of $h_{\max }=Y_{\max }-Y_{L}$ on the spillway crest, there are variations both in the length $L$ that is assigned to the crest and in the height of the dam so that, given a head hmax, the crest is able to discharge the flow rate $Q_{\text {omax }}=Q_{\text {imax }}$.

As a result, for a correct design of the outlet works, it is necessary to solve two problems [7-15]: (i) the hydrological problem of obtaining as accurate an estimate as possible of $Q_{\text {imax }}$ and (ii) the problem of correctly determining the dimensions of the outlet works and defining the values of $L$ and $Y_{\max }$.

Under hypothesis A, from a probabilistic point of view, $Q_{\text {imax }}$ is usually assumed to be equal to the value of $Q_{T R}$, defined as the value that the flood peak can reach once every $T$ years with an estimated risk $R$. The values of $T$ and $R$ are determined as a function of the type of dam and of the security coefficients that must be guaranteed to the areas downstream of the reservoir. To solve the second 
problem, it is necessary to first choose the type of outlet work that makes it possible to achieve the required functional characteristics at the lowest cost.

These two problems become substantially different in cases where, under hypothesis B, the reservoir can be counted on to reduce the flood wave. From the hydrological view point, it is not actually necessary to estimate the maximum flow rate $Q_{T R}$, corresponding to established values of $T$ and $R$, as it is more important to evaluate the flood hydrograph $Q_{i}(t)$ and the mass curve. In particular, it is of interest to assess the flow rate at flood peak $Q_{\text {imax }}$ and the cumulative flow $D_{e}$ that characterize each hydrograph in a flood event with a probability of taking place every $T$ years with an estimated risk $R$. In other words, it would be necessary to deduce the probabilities that must correspond to each of the variables $Q_{i}$ and $D_{i}$, associated simultaneously with the assigned values of $T$ and $R$, in the event in which they occur.

Analogously, the problem of designing outlet works becomes more complicated. Once the flood hydrographs have been set and having consequently fixed $Q_{i m a x}$ and $D_{i}$, a further unknown quantity that should be determined is the maximum design flow rate $Q_{\text {omax }}$ as well as the variables $Y_{\max }$ and $L$. If the spillways are made using uncontrolled crest, this problem can be solved by trial and error. In detail: successive values for $Q_{\text {omax }}$ are fixed, the corresponding values of $L$, and $Y_{\max }$ are deduced for each value of $Q_{\text {omax }}$ fixed, and, finally, the most convenient triplet of values is chosen for $Q_{\text {omax }}$, $L$, and $Y_{\max }$, respectively. In effect, once the algebraic relation is found that best fits the $W(h)$ law according to which the stored volume $W$ will vary as a function of the head on the crest and having fixed the value of $Q_{u \max }$, the problem of calculating $L$ and $Y_{\max }$ is solved through the system constituted by continuity eqn (1) and discharge eqn (2):

$$
\begin{gathered}
d W=\left(Q_{i}-Q_{o}\right) \cdot d t . \\
Q_{o}=\mu \cdot L \cdot \sqrt{2 g} \cdot h^{3 / 2} .
\end{gathered}
$$

In eqn (1), $Q_{i}$ and $Q_{o}$ still indicate the inflow and the outflow $\left(\mathrm{m}^{3} \cdot \mathrm{s}^{-1}\right)$, respectively, in time $d t$ (s), and $d W\left(\mathrm{~m}^{3}\right)$ indicates the volume of water that is stored in the reservoir in the same time interval. Equation (2) gives ( $g$ being the gravity acceleration $\left(\mathrm{m} \cdot \mathrm{s}^{-2}\right)$ ) the outflow $Q_{o}$ as a function of the above-defined length $L(\mathrm{~m})$ of head $h(\mathrm{~m})$ and of discharge coefficient $\mu$ that is in turn a function of the geometry of the system and again of the head $h$. In eqn (2), the level reached by the water is indicated with $Y(\mathrm{~m})$ and the increase $h=Y-Y_{o}$ above the maximum live storage capacity level $Y_{o}$ coincides with the head on the crest. Considering these facts, when choosing from different triplets of $Q_{\text {omax }}, L$ e $Y_{\text {max }}$, the one that can contain the costs of outlet and damming works to a minimum should be selected.

\section{NOTES ON OUTLET WORKS AND FLOOD MANAGEMENT}

To reduce the effect of a flood wave corresponding to the previously examined hypothesis $\mathrm{B}$, it is necessary to store a volume $W_{\max }$ exceeding the water level $Y_{L}$, representing a considerably greater percentage $P=W_{\max } / D_{i}$ of the total flow $D_{i}$ of the flood than in hypothesis A [2,3].

To store the necessary volumes exceeding $Y_{L}$, the level must rise by an amount that is inversely correlated to the surface area of the reservoir $S_{L}$ at the level $Y_{L}$. On the other hand, all other parameters being equal, the total flow of the flood $D_{i}$ increases with the surface $S_{B}$ of the underlying drainage basin. As a consequence, the maximum water level increases $h_{\max }=Y_{\max }-Y_{L}$ necessary to guarantee an assigned reduction $R_{Q}=Q_{\text {omax }} / Q_{\text {imax }}$ decreases the greater the $S_{L} / S_{B}$ ratio is. It follows that in assigning $Q_{\text {omax }}$, an acceptable reduction in the flood wave can only be expected when the $S_{L} / S_{B}$ ratio 
is sufficiently large $(>1 / 50 \div 1 / 60)$ [15]. Only in this case will the increase in the height of the dam needed to contain the rise $Y_{\max }-Y_{L}$ (required by the lamination effect) determine an increased building cost which, however, is certainly compensated by the reduction in cost of the outlet works due to the decrease in the maximum design flow rate $Q_{\text {omax }}$. When the $S_{L} / S_{B}$ ratio assumes very large values, relying on the reduction effect is the only technically acceptable solution. This case, under hypothesis A, would call for extremely long spillway crests with a very large increment in costs for the spillway inlet, in addition to the costs of scaling the remaining parts of the outlet works to the maximum flow rate $Q_{\text {omax }}=Q_{\text {imax }}$, which would certainly not be compensated by the lower cost of building the dam.

In fact it is possible to identify schemes with mobile mechanisms that allow the water to be contained at level $Y_{L}$ and which start operating automatically as the level increases beyond $Y_{L}$ to discharge an assigned flow rate $Q_{L}$ so that the water level does not rise in the reservoir. One possible scheme might be to use uncontrolled spillways at level $Y=Y_{L}$ together with a bottom outlet or midlevel outlet (i.e. placed at an intermediate level between the bottom outlet and the spillway crest) equipped with automated gates or command valves. When the mobile machinery comes into operation, as soon as the water level exceeds the $Y_{L}$ level, the following two targets are achieved. The first aim is the discharge of incoming flow rates up to the maximum value $Q_{L}$ keeping the water level in the reservoir at the determined level $Y_{L}$, thus not impinging on the storage capacity needed to control flood waves. The second aim is the containment of the discharged flow rate within the fixed value of $Q_{\text {omax }}$ when the water in the reservoir has reached the $Y_{\max }$ level and, as a result, committing all of the volume $W_{\max }$ assigned to flood control. To take into account emergency situations regarding blockages or anomalous functioning of the mobile gates, it will be appropriate to give a suitable value to the difference $\delta$ (for security reasons) between the maximum storage capacity level $Y_{\max }$ and the height of the dam.

It must further be noted that the use of an outlet device fitted with regulating gates allows for larger spillway crest levels. In normal operating situations, therefore, a larger volume of stored water can be counted on and made available to any other uses for which the reservoir is designed (drinking water, irrigation, electricity production), thus providing an indubitable economic advantage. A further advantage of this type of outlet device lies in the possibility to modify management of the flow rate discharged to deal with a different flood event evaluation or with problems linked to climate change and safeguarding the environment [16-19].

\section{OUTLET WORKS STUDIED ON A PHYSICAL MODEL}

The prototype of the outlet work studied on a physical model is composed of a spillway and a midlevel outlet built into a single structure (Fig. 1).

The spillway consists of an uncontrolled crest that is designed over a circle arc with an internal angle of $120^{\circ}$ (1/3 of bell-mouth spillway), with a total length of $L=30.60 \mathrm{~m}$, positioned at a height of $15.30 \mathrm{~m}$ above the threshold of the mid-level outlet. In particular, the mid-level outlet consists of four ports with a threshold level that will be considered as the benchmark level 0.00, equipped with vertical-lift gate, each $2.40 \times 3.20 \mathrm{~m}$ in size, and positioned underneath the crest of the spillway. The effluent flow rates from the four ports are convoyed through two paired water ducts with a variable cross-section to a vertical shaft and an outlet gallery.

For the works to be used for the expected lamination function, the mid-level outlet gates must open automatically as soon as the water level exceeds the crest of the spillway. Furthermore, the mid-level outlet must be capable of discharging a flow rate of $250 \mathrm{~m}^{3} \cdot \mathrm{s}^{-1}$, with a $15.30 \mathrm{~m}$ head.

For incoming flow rates above $250 \mathrm{~m}^{3} \cdot \mathrm{s}^{-1}$, and with the gates completely open, the water level increases, and the spillway is also activated. The flow rates thus discharged by the mid-level outlet 


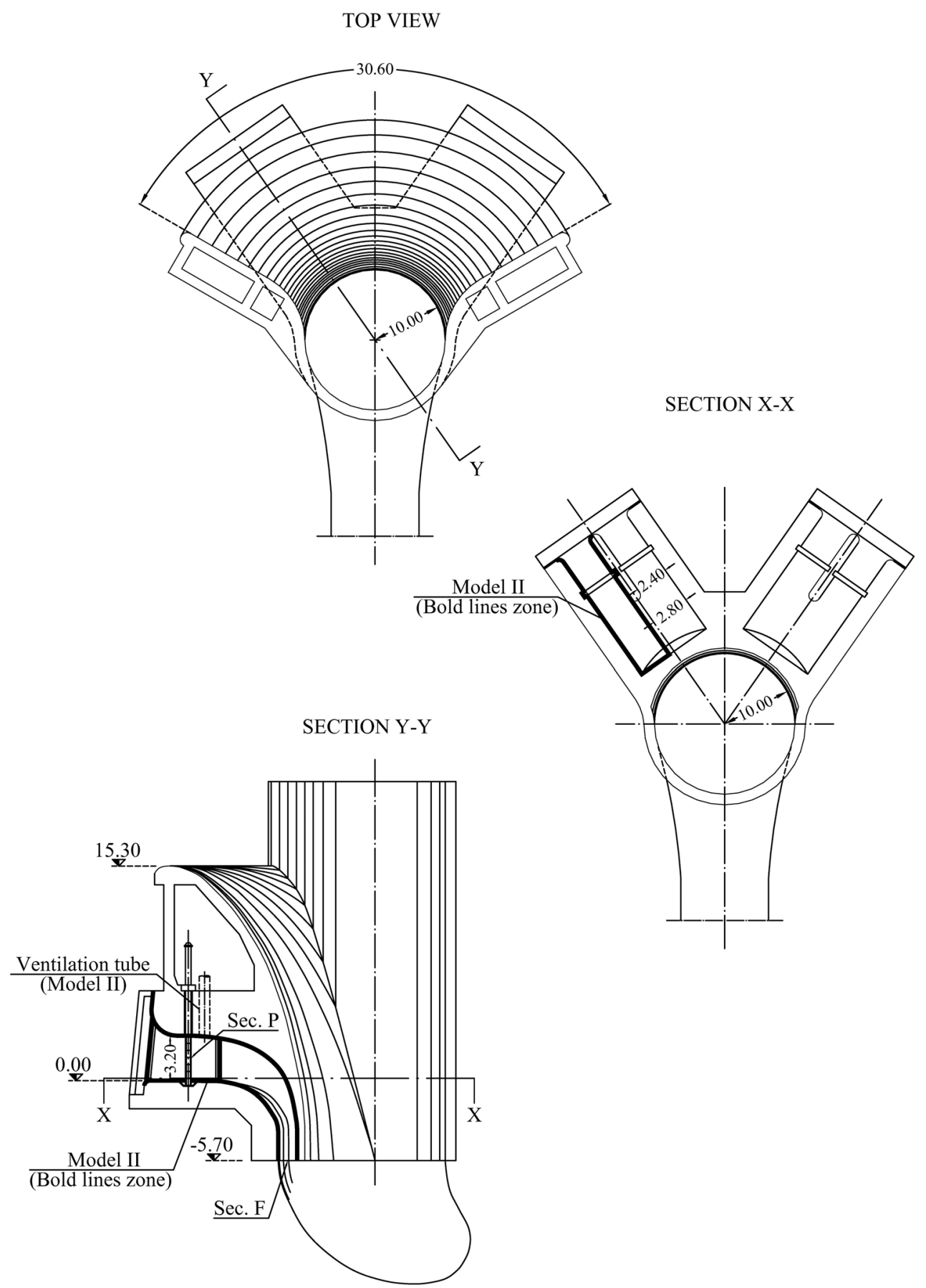

Figure 1: Prototype of the outlet works. 
and by the spillway increase till they reach a maximum value of $500 \mathrm{~m}^{3} \cdot \mathrm{s}^{-1}$, for a water level corresponding to a head on the crest of the spillway equal to $2.50 \mathrm{~m}$. In actual fact, the design of the spillway is such that, even in the event of mid-level outlet malfunctioning because of blockages to the gates, it would still be able to channel the total flow rate of $500 \mathrm{~m}^{3} \cdot \mathrm{s}^{-1}$, but with a head of $3.80 \mathrm{~m}$; thus, the spillway functions as an emergency outlet as well.

To study the hydraulic behavior of this interesting outlet system, two distinct physical models were produced. Froude's law of similitude was adopted since any losses due to friction are negligible and hydraulic performance primarily depends on gravitational and inertial forces.

Model I (geometric scale $\lambda=1 / 50$ ) reproduces the entire outlet works so it is still possible to refer to Fig. 1.

Model II (geometric scale $\lambda=1 / 25$ ) reproduces one of the four ports in the mid-level outlet, in particular a part of one of the two outlet pipes, defined by the two vertical and parallel planes on the edges of the span free of the gates (also visible in Fig. 1 - bold lines zone).

The models were positioned in two distinct, appropriately sized supply tanks endowed with a calm device making it possible to measure the head $h$ in the experimental tests without oscillations and disturbances.

The flow rates were derived from the supply circuit of the Laboratory of the Department of Hydraulic, Geotechnical and Environmental Engineering of the University of Naples, where the experimental tests were performed.

Because the data and elaborations of experimental data that have been compared were produced from two different models built on two different scales, it must first be said that the various measurements are reported with reference to the prototype (i.e. $\mathrm{m}$ and $\mathrm{m}^{3} \cdot \mathrm{s}^{-1}$ ).

The experimental tests conducted on Model I, regarding the whole outlet work, aimed to verify global hydraulic functioning, in relation to the discharge laws of the various ports and also to the flow rate in the vertical shaft and in the connecting section of the outlet gallery. In particular, the operational conditions were tested while working: (i) only the mid-level outlet (Series I); (ii) only the spillway (Series II); and (iii) both outlet devices at the same time (Series III). It must be noted that the tests from Series I coincide with the first phase of Series III (Table 1).

Table 1 reports the experimental tests and the values of the discharge coefficient $\mu_{I I}$ calculated through eqn (2) and relative to Series II.

All the results from the experimental tests are shown in Fig. 2, where $h$ and $Q$ respectively measure the head and the flow rate.

The most interesting $Q(h)$ law is clearly the one relating to test Series I and III. It can be noted that the curve $Q(h)$, obtained from both increasing and decreasing heads, can be separated into three distinct branches (Fig. 2). The first two branches represent the discharge laws of the midlevel outlet working as a weir (Phase I) and as a submerged orifice (Phase II), respectively. These first two phases fall into the tests of Series I. The third branch (Phase III) represents the law $Q(h)$ when, given a water depth of more than $15.30 \mathrm{~m}$, the spillway is also activated, thus achieving the conditions that belong with the tests of Series III. In Fig. 2, the experimental points are reported relative to the tests conducted on Model II regarding the discharge law of Phases I and II when only the mid-level outlet is operational. Moreover, the flow rates relative to the tests conducted on Model II were made homogeneous to those of Model I, taking into account the different scales and the fact that only one of the four ports of the mid-level outlet has been reproduced. The experimental tests elaborated from Model II show good agreement with those obtained from the tests run using Model I. 
G. Ciaravino \& L. Ciaravino, Int. J. of Design \& Nature and Ecodynamics. Vol. 7, No. 2 (2012)

Table 1: Experimental tests of Model I.

\begin{tabular}{lcccccc}
\hline Series & $Q[\mathrm{mc} / \mathrm{s}]$ & $h[\mathrm{~m}]$ & Series & $Q[\mathrm{mc} / \mathrm{s}]$ & $h[\mathrm{~m}]$ & $\mu_{I I}$ \\
\hline I & 73.72 & 2.75 & II & 77.78 & 0.99 & 0.583 \\
I & 114.91 & 3.67 & II & 116.67 & 1.34 & 0.555 \\
I & 129.93 & 3.94 & II & 127.81 & 1.43 & 0.551 \\
I & 155.87 & 4.41 & II & 156.45 & 1.66 & 0.540 \\
I & 178.72 & 6.86 & II & 197.99 & 1.96 & 0.532 \\
I & 195.93 & 9.63 & II & 219.20 & 2.07 & 0.543 \\
I & 199.93 & 10.02 & II & 256.33 & 2.38 & 0.515 \\
I & 215.67 & 12.20 & II & 270.47 & 2.39 & 0.540 \\
I & 231.58 & 15.01 & II & 314.66 & 2.69 & 0.526 \\
III & 251.02 & 15.63 & II & 364.16 & 3.00 & 0.517 \\
III & 323.50 & 16.47 & II & 386.79 & 3.12 & 0.518 \\
III & 385.73 & 17.00 & II & 427.27 & 3.34 & 0.516 \\
III & 459.35 & 17.50 & II & 482.60 & 3.63 & 0.515 \\
III & 502.05 & 17.80 & II & 514.07 & 3.79 & 0.514 \\
III & 516.19 & 17.92 & II & 549.78 & 3.97 & 0.513 \\
\hline
\end{tabular}

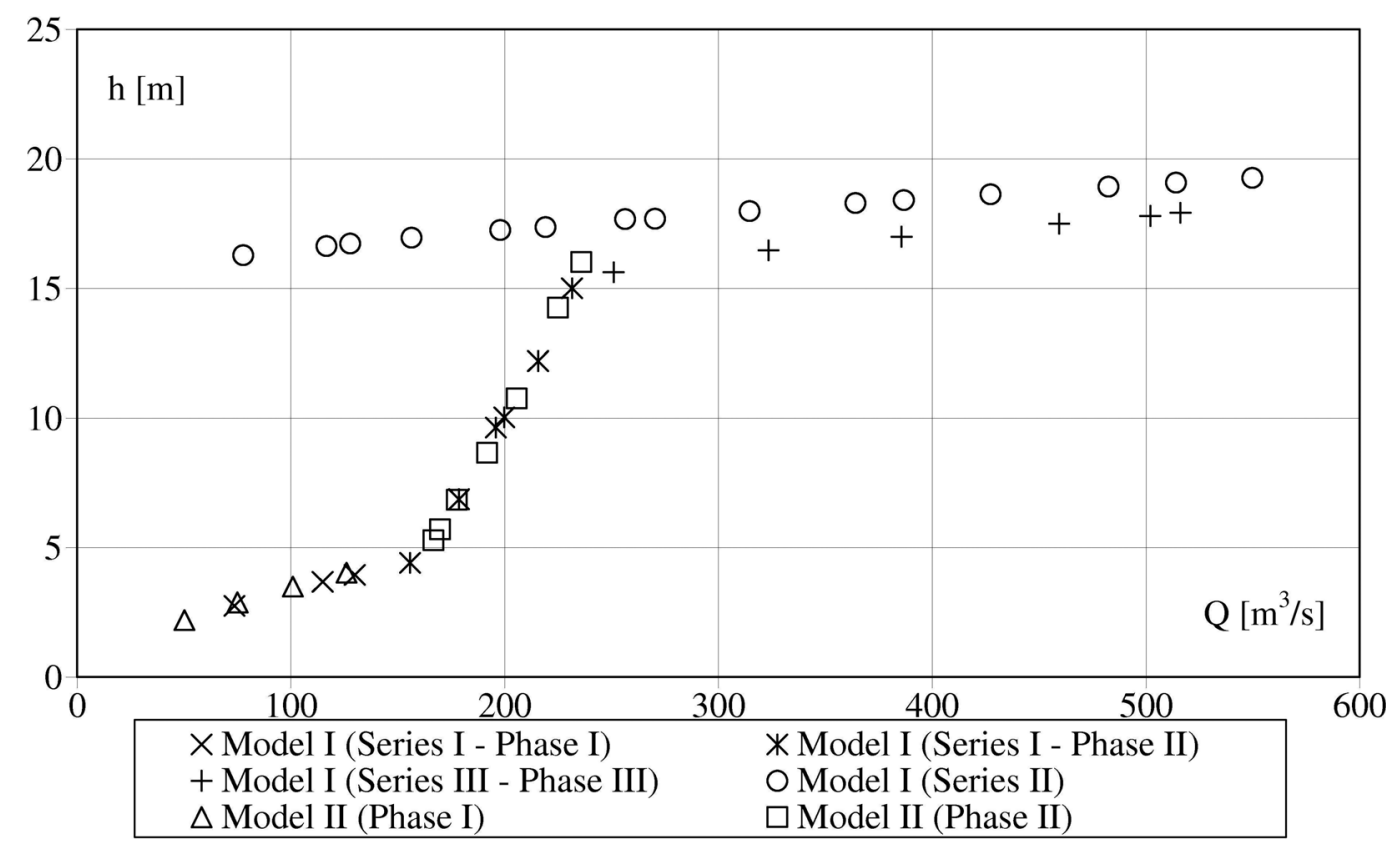

Figure 2: Experimental laws $Q(h)$. 


\section{DISCUSSION AND RESULTS}

The discharge laws make it clear that the maximum flow rates $Q$ disposed of by the mid-level outlet, for every value of the head $h$, depend on the size of the intake cross-sections of the four ports only in Phase I of the operation.

In Phase II, however, the flow rate $Q$ depends on the size assigned to the final cross-section of the duct, and the actual head $h$ is equal to the difference between the supply head and the height of the final cross-section of the duct, taking into account head losses.

In fact in Phase I, the $Q(h)$ law can be preliminarily deduced assuming that in correspondence with the inlet threshold critical conditions are established. More precisely, taking into account that the four ports have a rectangular section with a base $b=2.40 \mathrm{~m}$, if the total head $H_{c}$ (m) (sum of the water depth $h_{c}(\mathrm{~m})$ and kinetic height $V_{c}^{2} / 2 g(\mathrm{~m})$ under critical conditions) is calculated with the well-known relationship [20]:

$$
H_{c}=1.5 \cdot \sqrt[3]{\frac{Q^{2}}{g \cdot b^{2}}}
$$

the following equation can be obtained:

$$
h=H_{c}+K_{I} \frac{V_{c}^{2}}{2 g},
$$

in which

$$
K_{I} \cdot \frac{V_{c}^{2}}{2 g}=\Delta h_{I},
$$

represents the head loss due to the intake and the gate.

This loss, considering the gate to be completely open, can be estimated with some confidence, on the basis of the values of $h$ and $Q$, measured with Model II, in Phase I by using the average value 0.264 as $K_{I}$. On the other hand, in Phase II, and consequently from previous statements, it follows that

$$
h+y=\frac{Q^{2}}{2 g}\left(\frac{1}{A_{F}^{2} \cdot \mu_{F}^{2}}+K_{I I} \frac{1}{A_{P}^{2}}\right)
$$

where the following definitions can be stated: (i) $P$ and $F$, respectively, are the cross-sections in proximity of the gates and the terminal section of the pipe; (ii) $A_{P}$ and $A_{F}$ are the areas corresponding, respectively, to $\mathrm{P}$ and $\mathrm{F}$; (iii) $-y=-5.70 \mathrm{~m}$ is the level of cross-section $F$ compared to the bottom level of the initial cross-section (equal to the level of section $P$ ), in agreement with the previously assumed statements (Fig. 1 - bold lines zone).

From eqn (6), it is possible to extrapolate:

$$
K_{I I} \frac{Q^{2}}{2 g \cdot S_{P}^{2}}=\Delta h_{I I},
$$

where: (i) $\Delta h_{I I}$ indicates the localized head loss caused by the inlet and the gate, with a good approximation measured as the difference between the water level $h$ in the supply tank, for each 
Table 2: Quantities deduced from the experimental tests using Model II.

\begin{tabular}{rcccccc}
\hline$Q[\mathrm{mc} / \mathrm{s}]$ & $h[\mathrm{~m}]$ & $h_{A}[\mathrm{~m}]$ & $K_{I}$ & $K_{I I}$ & $K_{F}$ & $\mu_{F}$ \\
\hline 59.30 & 2.195 & - & 0.286 & - & - & - \\
88.65 & 2.875 & - & 0.299 & - & - & - \\
119.10 & 3.485 & - & 0.263 & - & - & - \\
148.83 & 4.015 & - & 0.209 & - & - & - \\
166.82 & 5.282 & 4.273 & - & 0.935 & 0.1414 & 0.936 \\
169.77 & 5.700 & 4.673 & - & 0.919 & 0.1463 & 0.934 \\
177.74 & 6.835 & 5.723 & - & 0.905 & 0.1512 & 0.932 \\
191.75 & 8.648 & 7.398 & - & 0.877 & 0.1366 & 0.938 \\
205.76 & 10.745 & 9.173 & - & 0.957 & 0.1198 & 0.945 \\
224.94 & 14.260 & 12.489 & - & 0.898 & 0.1463 & 0.934 \\
236.00 & 16.015 & 14.098 & - & 0.888 & 0.1317 & 0.940 \\
\hline
\end{tabular}

flow rate, and the level $h_{A}$ to which the water returns in the ventilation device positioned in section $P$ (in Model II) immediately downstream of the gate; (ii) $\mu_{F}$ indicates the discharge coefficient that corresponds to section $\mathrm{F}$, calculated assuming that the head is the difference between the level $h_{A}$ reached by the water in the ventilation tube and level $-y$ of cross-section F. On the basis of the results from these tests, the mean values for $K_{I I}$ and $\mu_{F}$ are equal to 0.912 and 0.937 , respectively. Also in the tests carried out using Model II it has been noted that: in Phase I, with free surface, the flow continuously runs in contact with the bottom in all sections of the outlet pipe; in Phase II, under pressure, the piezometric levels along the duct vary as an inverse function of the increases in the average velocity $V$ and the kinetic energy $V^{2} / 2 g$, due to reduction in the cross-section. From eqn (6) it is also possible, using simple considerations, to achieve a wellapproximated evaluation of head losses in Phase II in the curved part of the duct that precedes section $F$, which is equal to

$$
\Delta h_{F}=\frac{1-\mu_{F}^{2}}{\mu_{F}^{2}} \cdot \frac{Q^{2}}{2 g \cdot A_{F}^{2}},
$$

where the ratio

$$
\frac{1-\mu_{F}^{2}}{\mu_{F}^{2}}=K_{F},
$$

can be attributed with an average value of 0.139 . The following Table 2 presents the experimental and elaborated values of the above-discussed quantities from which it is possible to derive the above-mentioned average values. Moving on to Series II of the tests, carried out by closing the mid-level outlet, experimental measurements substantially confirm the trend of the discharge law deduced theoretically with a value of $\mu=0.5$. Actually the experimental discharge coefficient has an average value of 0.532 and the head at the crest corresponding to the maximum flow rate of $500 \mathrm{~m}^{3} \cdot \mathrm{s}^{-1}$ has a value of about $3.70 \mathrm{~m}$ against the theoretically predicted $3.80 \mathrm{~m}$ (Table 1). 
Furthermore, in the experimental tests using Model I, a sufficiently regular hydraulic operation was found in the vertical shaft and the sections leading to the outlet gallery, with the stream superficially aerated but compact and homogeneous toward the bottom. It can be noted that, under equal discharge conditions, the system works better when the mid-level outlet is also operational. The stream flowing from the spillway, in fact, runs on the stream from the mid-level outlet and is, from a certain point of view, dragged by the latter. Thus, the discharge from the spillway enters the gallery under much more regular flow conditions.

\section{CONCLUSION}

Climate change has created a greater uncertainty in the estimation of flood events and, as a result, outlet works should be designed in such a way that they can make it possible to manage and/or contain stored volumes during flood events to safeguard the environment and contain costs.

The simplest scheme normally used for outlet devices only has spillways with uncontrolled crest and with a discharge law traceable to eqn (2). In this case, it is recognized that to discharge percentagewise small flow rates $Q_{o}$, compared to the maximum predicted flow rate $Q_{\text {omax }}$, it is necessary to contain a volume of water $W_{i}$ that is, percentagewise, considerable compared to the maximum storage volume $W_{\max }$. On the other hand, it is clear that the inflow to the reservoir, when flood levels are on the increase, is still far from those for which it becomes necessary to take controlling action. In brief, a considerable percentage of the volume $W_{\max }$ would be committed in the case of much smaller incoming flow rates $Q_{i}$ than the maximum rate $Q_{\text {omax }}$ that can be discharged downstream.

Taking all this into account, to reduce the storage capacity $W_{\max }$ to be committed above $Y_{L}$ and at an equal percentage reduction effect $R_{Q}=Q_{\text {omax }} / Q_{\text {imax }}$ (and thus at an equal value of $Q_{\text {omax }}$ ), it is advantageous to minimize or possibly to nullify $W_{i}$. It is the duty of the project manager to always identify outlet work schemes that permit the achievement of this objective.

In light of these observations, the particular value of the outlet work studied is clear as it presents two interesting characteristics: (i) the fact that it is composed of two different outlets (spillway and mid-level outlet), the management of which allows the optimization of the lamination effect of the reservoir; (ii) the fact that the two outlets are incorporated into a single structure. These two characteristics allow a considerable economy in the construction costs of the outlet works, channeling works, dissipation works, and of the river protection works.

The tests conducted on the two models studied have permitted the identification of the control sections of the current and the evaluation of the necessary parameters for checking the hydraulic design of the works. In particular, for the spillway, the experimental discharge coefficient has been estimated to be 0.532 and thus higher than the theoretical value of 0.5 which, if adopted in the design phase, is precautionary in all head conditions (Table 1).

For the mid-level outlet, two operational modes have been identified: Phase I with the free surface flow; Phase II with the ports working under pressure. Phase I is influenced by the dimensions assigned to the intake section, while Phase II is influenced by the dimensions assigned to the terminal section of the outlet duct. In both phases, head losses in the inlet section, where the mobile gates are housed, play a considerable role. Therefore, the loss coefficients $K_{I}$ and $K_{I I}$ have been identified for the two phases and are equal on average to 0.264 and 0.912 , respectively (Table 2). In Phase II, for the final control cross-section $F$, an experimental discharge coefficient $\mu_{F}$ was determined that is equal on average to 0.937 (Table 2).

The experimental tests conducted have made it clear that under all conditions there is a very good hydraulic functioning even when the current from the spillway fuses with the current from 
the mid-level outlet. Indeed, it is noted that the drag exercised by the latter current on the former, given conditions of equal flow rate, actually improves the hydrodynamic function. In conclusion, during the tests the outlet works did not experience the drawback that sometimes occurs in the presence of vertical or sub-vertical pipes, at the foot of which the flow can cause an irregular dragging of air and hence a possible pulsed occlusion of the outlet pipe limiting its correct operation.

\section{REFERENCES}

[1] US Army Corps of Engineers (USACE), 1995. Hydraulic design of spillway, technical engineering and design guides as adapted form the US army corps of engineers, ASCE, 12, pp. 1-136, 1995.

[2] Sarginson, E.J., Flood control in reservoirs and storage pounds, Journal of Hydrology, 19, pp. 351-359, 1973. doi: http://dx.doi.org/10.1016/0022-1694(73)90107-8

[3] West, M.J.H., Flood control in reservoirs and storage pounds: a discussion, Journal of Hydrology, 23, pp. 67-71, 1974. doi: http://dx.doi.org/10.1016/0022-1694(74)90023-7

[4] Rossi, F., Fiorentino, M. \& Versace, P., Two Component Extreme Value Distribution for flood frequency analysis, Water Resources Research, 20(7), pp. 847-856, 1984. doi: http://dx.doi. org/10.1029/WR020i007p00847

[5] Beran, M., Hosking, J.R.M. \& Arnell, N., Comment on Two Component Extreme Value Distribution for flood frequency analysis by Rossi F., Fiorentino M., Versace P., Water Resources Research, 22, pp. 263-269, 1986. doi: http://dx.doi.org/10.1029/WR022i002p00263

[6] Rossi, F. \& Villani, P., Regional flood estimation methods, Coping with Floods, eds G. Rossi, N. Harmancioglu, V. Yevjevch, NATO ASI Series, Series E: Applied Sciences, Kluwer Academic Publishers, Dordrecht, the Netherlands, 257, pp. 135-169, 1994.

[7] Posey, C.J. \& Fu-Te, I., Functional design of flood control reservoirs, Paper n.2093 Transaction, ASCE, 105, 1940(a).

[8] Posey, C.J. \& Fu-Te, I., Additional remarks on functional design of flood control reservoirs, Investigation of the Iowa Institute of the Hydraulic Research, 1940(b).

[9] Wycoff, R.L. \& Singh, U.P., Preliminary hydrologic design of small flood detention reservoirs, Water Resource Bulletin, 12, pp. 337-349, 1976. doi: http://dx.doi. org/10.1111/j.1752-1688.1976.tb02683.x

[10] Chow, V.T., Maidment, D.R. \& Mays, L.W., Applied Hydrology. New York: Mc Graw Hill International Edition Civil Engineering Series, 1988.

[11] Haan, C.T., Statistical Methods in Hydrology. The Iowa State University Press: Ames, 1994.

[12] Guo, Y. \& Adams, B.J., 1998a. Hydrologic analysis of urban catchments with event-based probabilistic models 1. Runoff volume, Water Resources Research, 34(12), pp. 3421-3431, 1998(a). doi: http://dx.doi.org/10.1029/98WR02449

[13] Guo, Y. \& Adams, B.J., Hydrologic analysis of urban catchments with event-based probabilistic models 2. Peak discharge rate, Water Resources Research, 34(12), pp. 3433-3443, 1998(b). doi: http://dx.doi.org/10.1029/98WR02448

[14] Guo, Y. \& Adams, B.J., An analytical probabilistic approach to sizing flood control detention facilities, Water Resources Research, 35(8), pp. 2457-2468, 1999. doi: http://dx.doi. org/10.1029/1999WR900125

[15] Ciaravino, G., Role of outlet works in management and control of floods, Dams and Reservoirs, Societies and Environmental in the 21st Century, eds. Berga, L. et al., London, Taylor \& Francis Group, pp. 223-230, 2006. 
198 G. Ciaravino \& L. Ciaravino, Int. J. of Design \& Nature and Ecodynamics. Vol. 7, No. 2 (2012)

[16] Harnan, C. \& Stewardson M., Optimizing dam release rules to meet environmental flow targets, Rivers Research and Applications, 21, pp. 113-129, 2005. doi: http://dx.doi.org/10.1002/ rra.836

[17] Suen, J.P. \& Eheart, J.W., Reservoir management to balance ecosystem and human needs: incorporating the paradigm of the ecological flow regime, Water Resources Research, 42(3), WO3417, 2006. doi: http://dx.doi.org/10.1029/2005WR004314

[18] Jager, H. \& Smith, B.T., Sustainable reservoir operation: can we generate hydropower and preserve ecosystem values? River Research and Applications, 24(3), pp. 340-352, 2008. doi: http://dx.doi.org/10.1002/rra.1069

[19] Brekke, L.D., Maurer, E.P., Anderson, J.D., Dettinger, M.D., Townsley, E.S., Harrison A. \& Pruitt, T., Assessing reservoir operations risk under climate change, Water Resources Research, 45, WO4411, 2009. doi: http://dx.doi.org/10.1029/2008WR006941

[20] Streeter, V.L., Fluid Mechanics. 3rd ed. New York: Mc Graw-Hill Book Company, 1962. 